\title{
A Clinico-epidemiological study of patients with lichen planus and associated metabolic complications at a tertiary care centre
}

\author{
Astha Sharma1', Ashok K Khare², Lalit K Gupta², Asit Mittal'2, Sharad Mehta², \\ Manisha Balai ${ }^{2}$
}

${ }^{1}$ Consultant Dermatologist, Delhi, India, ${ }^{2}$ Department of Dermatology, RNT Medical College, Udaipur, Rajasthan, India

Corresponding author: Astha Sharma, MD, E-mail: sharma.astha.88@gmail.com

\begin{abstract}
Background: An association between lichen planus and systemic disorders such as diabetes mellitus, dyslipidemia and metabolic syndrome has been reported. Aim: To assess the clinico-epidemiological profile of lichen planus, evaluate prevalence of underlying metabolic complications and compare the clinical profile of patients with and without metabolic syndrome. Material and methods: All the patients with lichen planus attending dermatology out patient department of a tertiary care centre in South Rajasthan over a period of one year were studied. Patients with lichenoid drug eruptions and those receiving systemic treatment for lichen planus were excluded from the study. Statistical analysis was done using the chi - square test. A $p$ value $<0.05$ was considered significant. Results: A total of 270 patients of lichen planus were enrolled. Male to female ratio was found to be 0.76 : 1 . Maximum $(64 ; 23.7 \%)$ patients belonged to the age group of $31-40$ years. Classical morphology was the most common $(128 ; 47.4 \%)$ cutaneous pattern. Mucosal and nail involvement was seen in $80(29.6 \%)$ and 87 (32.2\%) patients respectively. Koebner phenomenon was present in $57(21.1 \%)$ patients. The investigations were completed by $175(64.8 \%)$ patients. Diabetes mellitus and hypertension were found in $12.6 \%$ (22/175) and $14.3 \%$ (25/175) patients respectively. The diagnostic criteria for dyslipidemia and metabolic syndrome were fulfilled by $39.4 \%$ (69/175) and 27.4\% (48/175) patients respectively. Majority (81.2\%) of the patients with metabolic syndrome belonged to age group 40 years and above, and oral and nail involvement was found to be more common in them. It is recommended that these patients should be screened for complications like diabetes, hypertension, dyslipidemia and metabolic syndrome. Conclusion: Significant numbers of lichen planus patients were found to have dyslipidemia and metabolic syndrome. Patients aged 40 years and above, with oral and nail involvement have higher propensity to be associated with metabolic syndrome and therefore such patients should be screened for metabolic complications. Timely screening and early intervention may reduce the risk of related morbidity and mortality. Limitations: Lack of control group is the drawback of our study. Age and sex matched comparative studies are required for confirmation of the results.
\end{abstract}

Key words: Lichen planus; Diabetes mellitus; Hypertension; Obesity; Dyslipidemia; Metabolic syndrome

\section{INTRODUCTION}

Lichen planus (LP) is a common, idiopathic, inflammatory condition involving the skin, mucous membranes, hair and nail, and characterized by pruritic, violaceous, flat-topped, polygonal papules that favour the extremities, particularly flexor aspects of the wrists and legs [1]. Its aetiology remains unknown and may be caused by a cell mediated immunological response where auto reactive cytotoxic $\mathrm{T}$ lymphocytes cause degeneration and destruction of keratinocytes.

The disease has been linked to metabolic complications like diabetes mellitus (DM) [2-4] and dyslipidemia [5-8]. A few studies [6,7] have documented the association of LP with metabolic syndrome (MS) also. Chronic

\footnotetext{
How to cite this article: Sharma A, Khare AK, Gupta LK, Mittal A, Mehta S, Balai M. A clinicoepidemiological study of patients with lichen planus and associated metabolic complications at a tertiary care centre. Our Dermatol Online. 2021;12(e):e6.

Submission: 02.05.2020; Acceptance: 10.01.2021

DOI: 10.7241 /ourd.2021e.6
} 
inflammation seen in LP may play a role in the pathogenesis of dyslipidemia and MS.

This study was carried out to determine the clinicoepidemiological profile of LP, to evaluate the prevalence of underlying metabolic complications, and compare the clinical profile of these patients with and without MS.

\section{MATERIALS AND METHODS}

This was a descriptive study with cross sectional analysis of patients of LP with and without MS. Approval for study was obtained from the Institutional ethics committee. Both male and female patients of all age groups presenting with clinical features of LP at the dermatology out patient department (OPD) over a period of one year were enrolled. Patients with lichenoid drug eruptions and those receiving systemic treatment for LP were excluded from the study.

After obtaining an informed written consent, a detailed history taking, cutaneous and mucosal examination and relevant investigations were done. Patients were evaluated for the presence of DM, hypertension (HT), obesity, dyslipidemia and MS.

Diabetes mellitus and HT were diagnosed as per the American Diabetes Association guidelines (ADA) [9] and the seventh report of the Joint National Committee on prevention, detection, evaluation, and treatment of high blood pressure (JNC VII) criteria [10] respectively. Body mass index (BMI) was calculated as weight (in kg)/ height ${ }^{2}$ $\left(\right.$ in $\mathrm{m}^{2}$ ) and values were interpreted as per World Health Organization (WHO) [11] guidelines (Table 1).

The presence of dyslipidemia was defined as per National Cholesterol Education Program Adult Treatment Plan (NCEP ATP) III criteria [12], if one of the following parameters were present:

- Total cholesterol (TC) $>200 \mathrm{mg} / \mathrm{dl}$

- Triglycerides (TG) $>150 \mathrm{mg} / \mathrm{dl}$

- Low density lipoprotein cholesterol (LDL-C) $>130 \mathrm{mg} / \mathrm{dl}$

- Patient on antihyperlipidemic drugs

Table 1: Diagnostic criteria [9-12] used in study for diabetes mellitus, hypertension, dyslipidemia and BMI.

\begin{tabular}{|c|c|c|}
\hline Diabetic profile & Fasting plasma glucose (mg/dl) & 2 hour post prandial plasma glucose ( $\mathrm{mg} / \mathrm{dl})$ \\
\hline $\begin{array}{l}\text { Normal glucose tolerance } \\
\text { Prediabetes } \\
\text { Diabetes mellitus }\end{array}$ & $\begin{array}{c}<100 \\
100-125(\mathrm{IFG}) \\
\geq 126\end{array}$ & $\begin{array}{c}<140 \\
140-199(\text { IGT }) \\
\geq 200\end{array}$ \\
\hline Blood Pressure & Systolic $(\mathrm{mmHg})$ & Diastolic $(\mathrm{mmHg})$ \\
\hline $\begin{array}{l}\text { Normal } \\
\text { Prehypertension } \\
\text { Stage } 1 \text { hypertension } \\
\text { Stage } 2 \text { hypertension } \\
\text { Isolated systolic hypertension }\end{array}$ & $\begin{array}{c}<120 \\
120-139 \\
140-159 \\
\geq 160 \\
\geq 140\end{array}$ & $\begin{array}{l}\text { and }<80 \\
\text { or } 80-89 \\
\text { or } 90-99 \\
\text { or } \geq 100 \\
\text { and }<90\end{array}$ \\
\hline Lipid profile & Value (mg/dl) & \\
\hline $\begin{array}{l}\text { Total cholesterol } \\
\text { Desirable } \\
\text { Borderline high } \\
\text { High }\end{array}$ & $\begin{array}{l}<200 \\
200-239 \\
>240\end{array}$ & \\
\hline $\begin{array}{l}\text { LDL cholesterol } \\
\text { Optimal } \\
\text { Near or above }\end{array}$ & $\begin{array}{c}<100 \\
100-129\end{array}$ & \\
\hline $\begin{array}{l}\text { Optimal } \\
\text { Borderline high } \\
\text { High } \\
\text { Very high }\end{array}$ & $\begin{array}{c}130-159 \\
160-189 \\
\quad>190\end{array}$ & \\
\hline $\begin{array}{l}\text { HDL cholesterol } \\
\text { Low } \\
\text { Normal } \\
\text { High }\end{array}$ & $\begin{array}{c}<40 \\
40-60 \\
>60\end{array}$ & \\
\hline $\begin{array}{l}\text { Triglycerides } \\
\text { Normal } \\
\text { Borderline-high } \\
\text { High } \\
\text { Very high }\end{array}$ & $\begin{array}{c}<150 \\
150-199 \\
200-499 \\
\geq 500\end{array}$ & \\
\hline BMI & Value $\left(\mathrm{kg} / \mathrm{m}^{2}\right)$ & \\
\hline $\begin{array}{l}\text { Underweight } \\
\text { Normal } \\
\text { Overweight } \\
\text { Obese } \\
\text { Extremely obese }\end{array}$ & $\begin{array}{c}<18.5 \\
18.5-24.9 \\
25-29.99 \\
\geq 30 \\
\geq 40\end{array}$ & \\
\hline
\end{tabular}

IFG: Impaired fasting glucose, IGT: Impaired glucose tolerance,

LDL: Low density lipoprotein, HDL: High density lipoprotein, BMI: Body mass index 
Metabolic syndrome was diagnosed using NCEP ATP III criteria [13]. Diagnosis was made when three or more criteria were present, including:

- Waist circumference of more than $102 \mathrm{~cm}$ in men or more than $88 \mathrm{~cm}$ in women

- Blood pressure level > 130/85 mmHg or use of antihypertensive medication

- Fasting plasma glucose (FPG) levels $>100 \mathrm{mg} / \mathrm{dl}$ or on drug treatment for elevated glucose

- Fasting triglyceride (TG) levels $>150 \mathrm{mg} / \mathrm{dl}$ or on drug treatment for elevated TG

- Fasting high density lipoprotein cholesterol (HDL-C) levels $<40 \mathrm{mg} / \mathrm{dl}$ in men or $<50 \mathrm{mg} / \mathrm{dl}$ in women or on drug treatment for reduced HDL-C.

Based on the fulfillment of these criteria, the patients were divided into two groups - patients with MS and patients without MS. The two groups were compared with each other with respect to age and sex distribution, duration, initial site of onset, associated symptoms, clinical variants, mucosal and nail affection. Chi-square test was used to carry out statistical analysis. $p$ value $<0.05$ was considered statistically significant.

\section{RESULTS}

A total of 270 patients of LP were enrolled and their clinico-epidemiological profile was studied. Of these, 175 (64.8\%) patients returned with investigation reports to get evaluated for metabolic complications. A prevalence of $0.34 \%$ was found in our OPD during the study period. Female preponderance was seen with male: female ratio being 0.76: 1. Maximum $(64 / 270 ; 23.7 \%)$ number of patients belonged to the age group of $31-40$ years. Mean age of onset of lesions was $37.2+16.4$ years. Pediatric age group $(<18$ years) comprised $38(14.1 \%)$ patients. Most (110/270; $40.7 \%$ ) patients presented between 1 to 6 months of onset. The most $(98 / 270 ; 36.3 \%)$ common initial site of lesion was lower extremity followed by upper extremity $(77 / 270 ; 28.5 \%)$. Cutaneous involvement alone $(143 / 270 ; 53 \%)$ was the most common presentation. Classical morphology was the most common cutaneous presentation (49.3\%). Mucosa was affected in $80(29.6 \%)$ patients; $21(7.8 \%)$ patients had only mucosal involvement. Reticular pattern $(68 / 80 ; 87.2 \%)$ was commonest mucosal pattern. Nail involvement was seen in $87(32.2 \%)$ patients with longitudinal melanonychia $(40 / 87 ; 46 \%)$ being the most common presentation. Koebner phenomenon was present in $57(21.1 \%)$ patients. Family and past history of LP was revealed by $2(0.7 \%)$ and $30(11.1 \%)$ patients respectively (Table 2 ).

The mean BMI of patients with LP in the study was $23.2 \mathrm{~kg} / \mathrm{m}^{2}$. Around $25.2 \%$ of patients were found to have $\mathrm{BMI} \geq 25 \mathrm{~kg} / \mathrm{m}^{2}$. Of the 175 patients who came for follow up, $22(12.6 \%)$ patients were found to be diabetic, while 69 (39.4\%) and 25 (14.3\%) patients were prehypertensive and hypertensive respectively. The diagnostic criteria for dyslipidemia and MS

Table 2: clinico-epidemiological profile of patients with lichen planus $(n=270)$

\begin{tabular}{|c|c|c|c|}
\hline Parameter & $\begin{array}{c}\text { Male } \\
(n=117)\end{array}$ & $\begin{array}{l}\text { Female } \\
(n=153)\end{array}$ & $p$ value \\
\hline \multicolumn{4}{|l|}{ Age group (years) } \\
\hline Upto 20 & 27 & 19 & 0.02 \\
\hline $21-30$ & 26 & 31 & 0.69 \\
\hline $31-40$ & 27 & 37 & 0.83 \\
\hline $41-50$ & 17 & 32 & 0.17 \\
\hline $51-60$ & 11 & 19 & 0.43 \\
\hline Above 60 & 9 & 15 & 0.55 \\
\hline \multicolumn{4}{|l|}{ Duration } \\
\hline$<1 \mathrm{~m}$ & 27 & 37 & 0.83 \\
\hline $1-6 m$ & 46 & 64 & 0.67 \\
\hline$>6-12 \mathrm{~m}$ & 18 & 24 & 0.95 \\
\hline$>1$ year & 8 & 15 & 0.39 \\
\hline$>3$ year & 18 & 13 & 0.08 \\
\hline \multicolumn{4}{|l|}{ Initial site of LP } \\
\hline Scalp & 3 & 1 & 0.19 \\
\hline Face & 6 & 4 & 0.28 \\
\hline Neck & 5 & 3 & 0.27 \\
\hline Trunk & 8 & 13 & 0.61 \\
\hline Upper limb & 29 & 48 & 0.24 \\
\hline Lower limb & 40 & 58 & 0.53 \\
\hline Genital skin & 6 & 2 & 0.07 \\
\hline Mucosa & 19 & 24 & 0.90 \\
\hline Nail & 1 & 0 & 0.25 \\
\hline \multicolumn{4}{|l|}{ Symptomatology* } \\
\hline Itching & 91 & 119 & 0.99 \\
\hline Irritation & 13 & 22 & 0.43 \\
\hline Pain & 8 & 15 & 0.38 \\
\hline None & 8 & 9 & 0.75 \\
\hline \multicolumn{4}{|c|}{ Spectrum of different presentations } \\
\hline Only cutaneous & 55 & 88 & 0.25 \\
\hline Only mucosal & 8 & 13 & 0.61 \\
\hline Only nail & 1 & - & 0.25 \\
\hline Cutaneous +Mucosal & 7 & 12 & 0.55 \\
\hline Cutaneous + Nail & 25 & 21 & 0.09 \\
\hline Mucosal + Nail & 9 & 11 & 0.87 \\
\hline Cutaneous+Mucosal+Nail & 12 & 8 & 0.12 \\
\hline \multicolumn{4}{|l|}{ Cutaneous variants* } \\
\hline Classical & 49 & 79 & 0.112 \\
\hline Follicular & 4 & 3 & 0.455 \\
\hline Hypertrophic & 15 & 11 & 0.120 \\
\hline Linear & 8 & 9 & 0.749 \\
\hline Actinic & 6 & 2 & 0.067 \\
\hline Pigmentosus & 7 & 18 & 0.104 \\
\hline Eruptive & 5 & 10 & 0.421 \\
\hline Annular & 8 & - & $0.001 \dagger$ \\
\hline \multicolumn{4}{|l|}{ Mucosal affection } \\
\hline Only oral & 33 & 41 & 0.74 \\
\hline Only genital & 3 & 1 & 0.19 \\
\hline Oral+genital & 2 & 0 & 0.10 \\
\hline \multicolumn{4}{|l|}{ Nail affection } \\
\hline Present & 47 & 40 & $0.015 \dagger$ \\
\hline Absent & 70 & 113 & \\
\hline \multicolumn{4}{|l|}{ Koebnerisation } \\
\hline Present & 24 & 33 & 0.83 \\
\hline Absent & 93 & 120 & \\
\hline
\end{tabular}

*some patients had more than one entity †Statistically significant 
were fulfilled by $39.4 \%(69 / 175)$ and $27.4 \%$ (48/175) respectively (Table 3). Mean serum uric acid level, a marker of oxidant stress, was $4.35 \mathrm{mg} / \mathrm{dl}$.

Comparison of clinico-epidemiological profile of patients with and without MS revealed that maximum (81.2\%) number of patients fulfilling the criteria of MS were in age group 40 years and more. The patients with oral mucosal and nail involvement were more commonly associated with MS. However, statistically significant difference was not noticed in patients with and without MS with respect to the duration, initial site, symptomatology and types of cutaneous variants (Table 4).

\section{DISCUSSION}

Lichen planus mostly affects the middle-aged adults. Maximum number of patients belonged to the age group of 31-40 years as observed in other reports [14-17]. Female predominance was recorded; M:F ratio being $0.76: 1$. This is in accordance with some other studies [17-20]. Extremities (64.8\%) were the

Table 3: Investigative findings of patients with lichen planus $(n=175)$

\begin{tabular}{|c|c|c|c|}
\hline Parameter & M (70) & $F(105)$ & $p$ value \\
\hline Blood glucose level & & & 0.05 \\
\hline Normal & 40 & 72 & \\
\hline IFG & 25 & 22 & \\
\hline IGT & 23 & 18 & \\
\hline DM & 7 & 15 & \\
\hline Blood pressure & & & 0.126 \\
\hline Normotensive & 27 & 54 & \\
\hline Prehypertensive & 34 & 35 & \\
\hline Hypertensive & 9 & 16 & \\
\hline $\mathrm{BMI}\left(\mathrm{kg} / \mathrm{m}^{2}\right)$ & & & 0.79 \\
\hline$<18.5$ (underweight) & 14 & 18 & \\
\hline $18.5-24.9$ (normal) & 39 & 59 & \\
\hline $25.0-29.9$ (overweight) & 16 & 23 & \\
\hline $30.0-39.9$ (obese) & 1 & 4 & \\
\hline$\geq 40$ (extremely obese) & 0 & 1 & \\
\hline Total cholesterol & & & 0.246 \\
\hline Desirable & 51 & 64 & \\
\hline Borderline high & 10 & 24 & \\
\hline High & 9 & 17 & \\
\hline Triglyceride & & & 0.33 \\
\hline Normal & 57 & 79 & \\
\hline High & 13 & 26 & \\
\hline HDL - Cholesterol & & & $0.005 \dagger$ \\
\hline Normal & 34 & 56 & \\
\hline Low & 33 & 30 & \\
\hline High & 3 & 19 & \\
\hline LDL - Cholesterol & & & 0.916 \\
\hline Optimal & 39 & 60 & \\
\hline Near or above optimal & 22 & 29 & \\
\hline Borderline high & 6 & 10 & \\
\hline High & 3 & 5 & \\
\hline Very high & 3 & 19 & \\
\hline VLDL & & & 0.33 \\
\hline Normal & 57 & 79 & \\
\hline High & 13 & 26 & \\
\hline
\end{tabular}

IFG: Impaired fasting glucose, IGT: Impaired glucose tolerance,

DM: Diabetes mellitus,BMI: Body mass index, LDL: Low density lipoprotein, HDL: High density lipoprotein,VLDL: Very low density lipoprotein,

† Statistically significant most common initial site of affection, as reported in some studies [14,21]. Compared to upper extremity, lower extremity $(98 / 270 ; 36.3 \%)$ was more commonly involved as reported by others [16-18]. Like in most other studies [14-20,22], classical LP was the most common variant. However, Anbar et al [21], in a study from tropical area of Egypt, found actinic LP as the most common variant. Nail affection has been reported to occur with variable frequency ranging from $6.4 \%$ to $18 \%[14,16,18,21]$. A relatively higher occurence $(32.2 \%)$ of nail involvement was seen in our study. Koebner phenomenon which presents as development of similar pathologic lesions along the line of trauma, is frequently seen in LP. It was present in $21.1 \%(57 / 270)$ patients, compared to $37.5 \%$ in a study by Khondker et al [22].

Studies have found defective carbohydrate expression in the epidermal cells, as a result of which, an increased prevalence of DM and carbohydrate intolerance has been observed in patients with LP [2-4], especially oral LP. In our study, 175 patients out of 270 patients could be evaluated further for metabolic complications. Of them 26.9\% (47/175) patients had impaired fasting glucose (IFG) and $12.6 \%(22 / 175)$ had DM as per the ADA criteria.

The mean BMI of our patients was found to be $23.2 \mathrm{~kg} / \mathrm{m}^{2}$, compared to $26.4 \mathrm{~kg} / \mathrm{m}^{2}$ and $24.26 \mathrm{~kg} / \mathrm{m}^{2}$ reported by Santiago et $\mathrm{al}^{6}$ and Hashba H [23] et al respectively.

Lichen planus is an immune-mediated disease involving Langerhans cells and T lymphocytes. The stimulated lymphocytic infiltrate is epidermotropic and attacks keratinocytes, resulting in generation of reactive oxygen species and release of cytokines such as TNF- $\alpha$, IL-6, IL-10, and IL-4. This could explain the association of LP with dyslipidemia, as chronic inflammation has been suggested as a component of the metabolic syndrome [6]. Dreiher et al [5] showed the connection between dyslipidaemia and LP in a large number of study participants. Santiago et al [6] analysed various parameters of metabolic syndrome and found a similar association with dyslipidemia. But no significant differences were observed in glucose levels, blood pressure and abdominal obesity in their study. However Saleh et al [7] showed that patients with lichen planus had higher markers of both metabolic and cardiovascular risk factors. A recent Indian study by Panchal et al [8], also demonstrated dyslipidemia in LP compared to controls. As per NCEP ATP III criteria for dyslipidemia, 39.4\% (69/175) patients, comprising of 
Table 4: Clinicoepidemiological profile of patients with and without Metabolic Syndrome

\begin{tabular}{|c|c|c|c|}
\hline Parameter & Patients with MS $(n=48)$ & Patients without MS $(n=127)$ & $\mathrm{p}$ value \\
\hline \multicolumn{4}{|l|}{ Age group (years) } \\
\hline Upto 20 & 0 & 26 & \multirow[t]{6}{*}{$<0.001 \dagger$} \\
\hline $21-30$ & 0 & 35 & \\
\hline $31-40$ & 9 & 37 & \\
\hline $41-50$ & 19 & 14 & \\
\hline $51-60$ & 11 & 10 & \\
\hline Above 60 & 9 & 5 & \\
\hline \multicolumn{4}{|l|}{ Sex } \\
\hline Male & 16 & 54 & \multirow[t]{2}{*}{0.37} \\
\hline Female & 32 & 73 & \\
\hline \multicolumn{4}{|l|}{ Duration } \\
\hline$<1 \mathrm{~m}$ & 8 & 34 & \multirow[t]{5}{*}{0.196} \\
\hline $1-6 m$ & 18 & 51 & \\
\hline$>6-12 \mathrm{~m}$ & 8 & 16 & \\
\hline$>1$ year & 5 & 11 & \\
\hline$>3$ year & 9 & 15 & \\
\hline \multicolumn{4}{|l|}{ Initial site of LP } \\
\hline Scalp & 2 & 2 & \multirow[t]{9}{*}{0.55} \\
\hline Face & 0 & 5 & \\
\hline Neck & 1 & 3 & \\
\hline Trunk & 3 & 12 & \\
\hline Upper limb & 13 & 38 & \\
\hline Lower limb & 18 & 41 & \\
\hline Genital skin & 1 & 5 & \\
\hline Mucosa & 9 & 21 & \\
\hline Nail & 1 & 0 & \\
\hline \multicolumn{4}{|l|}{ Symptomatology* } \\
\hline Itching & 35 & 99 & \multirow[t]{4}{*}{0.43} \\
\hline Irritation & 10 & 14 & \\
\hline Pain & 5 & 15 & \\
\hline None & 2 & 7 & \\
\hline \multicolumn{4}{|c|}{ Spectrum of different presentations } \\
\hline Only cutaneous & 16 & 73 & \multirow[t]{7}{*}{$<0.001 \dagger$} \\
\hline Only mucosal & 2 & 11 & \\
\hline Only nail & 0 & 0 & \\
\hline Cutaneous +Mucosal & 7 & 8 & \\
\hline Cutaneous + Nail & 11 & 19 & \\
\hline Mucosal + Nail & 8 & 9 & \\
\hline Cutaneous+Mucosal+Nail & 4 & 7 & \\
\hline \multicolumn{4}{|l|}{ Cutaneous variants* } \\
\hline Classical & 23 & 62 & 0.91 \\
\hline Follicular & 3 & 4 & 0.35 \\
\hline Hypertrophic & 8 & 10 & 0.08 \\
\hline Linear & 2 & 8 & 0.58 \\
\hline Actinic & 0 & 4 & 0.21 \\
\hline Pigmentosus & 2 & 11 & 0.31 \\
\hline Eruptive & 0 & 10 & 0.04 \\
\hline Annular & 1 & 4 & 0.70 \\
\hline \multicolumn{4}{|l|}{ Mucosal affection } \\
\hline Only oral & 21 & 33 & $0.02 \dagger$ \\
\hline Only genital & 0 & 0 & - \\
\hline Oral+genital & 0 & 2 & 0.38 \\
\hline \multicolumn{4}{|l|}{ Nail affection } \\
\hline Present & 23 & 35 & \multirow{2}{*}{$0.01 \dagger$} \\
\hline Absent & 25 & 92 & \\
\hline
\end{tabular}

*some patients had more than one entity

tstatistically significant

25 males and 44 females, fulfilled the diagnostic criteria. This is almost similar to figure of Dreiher et $\mathrm{al}^{5}(42.5 \%)$ and Kuntoji et al [24] (38\%). Panchal et al [8] reported dyslipidemia in $30 \%$ patients while Santiago et $\mathrm{al}^{6}$ and Saleh et al [7] found higher occurence of dyslipidemia in $61 \%$ and $100 \%$ cases respectively.

Metabolic Syndrome is a collection of multiple risk factors (obesity, hypertension, dyslipidemia and insulin resistance) which increase the incidence of cardiovascular disease, diabetes and stroke. In our study it was found that
$27.4 \%$ (48/175) patients fulfilled the criteria of MS which is similar to that reported by Santiago et al (27\%) [6]. A higher occurence of MS has been documented by Saleh et al (77.5\%) [7], Hashba Het al (35.7\%) [23] and Kurian $\mathrm{G}$ et al [25] (45\%) in patients with LP, whereas Kuntoji et al [24] reported a prevelance of $6 \%$.

Increased oxidative stress has also found to be associated with LP $[8,26]$. As uric acid is one of the important antioxidants in plasma, level of serum uric acid is expected to be reduced. A few studies [26,27] 
have reported significantly decreased levels of serum uric acid. However, mean serum uric acid levels were within normal range in our patients.

On comparing the profile of patients of LP with or without MS, it was observed that majority of the patients with MS belonged to the age groups above 40 years. This observation was highly significant statistically. Oral mucosal and nail involvement was more common in patients with MS than patients without MS and this too was statistically significant.

Thus, patients of LP aged 40 years and above, with oral mucosal and nail affection should be evaluated for complications like diabetes, hypertension, dyslipidemia and metabolic syndrome.

As significant numbers of patients were found to have dyslipidemia and metabolic syndrome in our study, a routine screening and early intervention may reduce the risk of related morbidity and mortality. Lack of control group is the major drawback of the study. Further age and sex matched case-control studies are required to confirm the association of LP with dyslipidemia and MS.

\section{Statement of Human and Animal Rights}

All the procedures followed were in accordance with the ethical standards of the responsible committee on human experimentation (institutional and national) and with the 2008 revision of the Declaration of Helsinki of 1975.

\section{Statement of Informed Consent}

Informed consent for participation in this study was obtained from all patients

\section{REFERENCES}

1. Boyed AS, Neldner KH. Lichen planus. J Am Acad Dermatol. 1991;25:593-619.

2. Najmosadat A, Mehrdad M, Shadi P, Shadi G. Prevalence of diabetes mellitus and impaired fasting blood glucose in patients with Lichen Planus. Med J Islam Repub Iran. 2012;26:22-6.

3. Romero MA, Seoane J, Varela-Centelles P, Diz Dios P, García Pola MJ. Prevalence of diabetes mellitus amongst oral lichen planus patients. Clinical and pathological characteristics. Med Oral. 2002;7:121-9.

4. Seyhan M, Ozcan H, Sahin I, Bayram N, Karincaoğlu Y. High prevalence of glucose metabolism disturbance in patients with lichen planus. Diabetes Res Clin Pract. 2007;77:198-202.

5. Dreiher J, Shapiro J, Cohen AD. Lichen planus and dyslipidaemia: a case-control study. Br J Dermatol. 2009;161:626-9.

6. Arias-Santiago S, Buendía-Eisman A, Aneiros-Fernández J, Sierra Girón-Prieto M, Gutiérrez-Salmerón MT, Mellado VG, et al. Lipid levels in patients with lichen planus: a case-control study. J Eur Acad Dermatol Venereol. 2011;25:1398-401.
7. Saleh N, Samir N, Megahed H, Farid E. Homocysteine and dyslipidaemia with lichen planus and metabolic syndrome. J Eur Acad Dermatol Venereol. 2014;28:1507-13.

8. Panchal H, Ray S, Munshi R, Bhalerao S, Nayak C. Alterations in Lipid Metabolism and Antioxidant Status in Lichen Planus. Indian J Dermatol. 2015;60:439-44.

9. American Diabetes Association: Standards of medical care in diabetes-2011. Diabetes Care. 2011;34 Suppl 1:S11-61.

10. Chobanian AV, Bakris GL, Black HR, Cushman WC, Green LA, Izzo JL Jr, et al. The seventh report of the Joint National Committee on Prevention, Detection, Evaluation, and Treatment of High Blood Pressure: The JNC 7 report. JAMA. 2003;289:2560-72.

11. WHO expert consultation. Appropriate body-mass index for Asian populations and its implications for policy and intervention strategies. Lancet. 2004;363:157-63.

12. Executive Summary of The Third Report of the National Cholesterol Education Program (NCEP) Expert Panel on Detection, Evaluation, and Treatment of High Blood Cholesterol In Adults (Adult Treatment Panel III). JAMA. 2001;285:2486-97.

13. Grundy SM, Cleeman JI, Daniels SR, Donato KA, Eckel RH, Franklin BA, et al. Diagnosis and management of the metabolic syndrome: an American heart association/national heart lung and blood institute scientific statement. Circulation. 2005;112:2735-52.

14. Bhattacharya M, Kaur I, Kumar B. Lichen planus: A clinical and epidemiological study. J Dermatol. 2000;27:576-82.

15. Singh OP, Kanwar AJ. Lichen planus in India: an appraisal of 441 cases. Int J Dermatol. 1976;15:752-6.

16. Kachhawa D, Kachhawa V, Kalla G, Gupta L. A clinico-aetiological profile of 375 cases of lichen planus. Indian J Dermatol Venereol Leprol. 1995;61:276-9.

17. Ireddy $S$, Udbalkar S. Epidemiological study of Lichen Planus. BMR Med. 2014;1:1-9.

18. Abdallat SA, Maaita TJ. Epidemiological and clinical features of lichen planus in Jordanian patients. Pak J Med Sci J. 2007;23:92-4.

19. Garg V, Nangia A, Logani B, Sharma R C. Lichen Planus-a Clinicohistopathological. Indian J Dermatol Venereol Leprol. 2000;66:193-5.

20. Nangia A, Kumar V, Logani KB. An immunopathological study of lichen planus. Indian J Dermatol Venereol Leprol. 2000;66:76-8.

21. Anbar T, Barakat M, Sahar FG. A clinical and epidemiological study of lichen planus among Egyptians of AL-Minya province. Dermatol Online J. 2005;11:4.

22. Khonddker L, Wahab MA, Khan SI. Profile of lichen planus in Bangladesh. Mymensingh Med J. 2010;19:250-3.

23. Hashba H, Bifi J, Thyvalappil A, Sridharan R, Sreenivasan A, Mathew P. Prevalence of metabolic syndrome in patients with lichen planus: A cross-sectional study from a tertiary care center. Indian Dermatol Online J. 2018;9:304-8.

24. Kuntoji V, Kudligi C, Bhagwat PV, Manasa D.R, Sharma A, Andanappanavar V, et al. Dyslipidemia and metabolic syndrome in patients with lichen planus: A case-control study. J Pak Assoc Dermatol. 2016;26:290-7.

25. Kurian G, Krishnan S, Shakthi P. A prospective case control study on metabolic syndrome in lichen planus in a tertiary care centre. Int J Res Dermatol. 2017;3:427-32.

26. Battino M, Greabu M, Totan A, Bullon P, Bucur A, Tovaru S. Oxidative stress markers in oral lichen planus. Biofactors. 2008;33:301-10.

27. Chakraborti G, Biswas R, Chakraborti S, Sen PK. Altered serum uric acid level in lichen planus patients. Indian J Dermatol. 2014;59:558-61.

Copyright by Astha Sharma, et al. This is an open-access article distributed under the terms of the Creative Commons Attribution License, which permits unrestricted use, distribution, and reproduction in any medium, provided the original author and source are credited. Source of Support: Nil, Conflict of Interest: None declared. 